\title{
Notes of Guidance for Assessors on Advisory (Consultant) Appointments Committees
}

The Court of Electors considered that it might be of interest to members if the following Notes of Guidance were published in the Bulletin. These Notes are sent to all College Assessors on Advisory (Consultant) Appointment Committees.

R. G. PrIEst
Registrar

Registrar

1. The College attaches great importance to the duties of its representatives on Advisory Appointments Committees as they play an important part in safeguarding the standards of psychiatric practice.

2. The representative of the College has two functions. The first is to advise the Committee to exclude those candidates who do not meet the required standards. This can mean all candidates. (The standards laid down by the College are set out in Appendix I.) The representatives of the College are asked to make sure that they are completely satisfied that candidates applying for Consultant posts in general psychiatry have undertaken sufficient training in general adult psychiatry in a post in the Senior Registrar grade which has been approved by the JCHPT. The second function is to assist in the selection of the most able candidate among those eligible who are judged to meet the particular requirements of the advertised post. The relevant Regulation is as follows:

The Committee shall consider all applications so referred to them and they shall select from the applications the person or persons the Committee shall consider suitable for the appointment and submit the appropriate name or names to the Authority together with any comments they may wish to make [National Health Service (Appointment of Consultants) Regulation 1974 (S.I. 1974, No. 361)]

3. The College reminds its representatives that it attaches great importance to the criteria set out in Appendix I. It is open to a College representative on an Advisory Appointments Committee to send a minority report to the Chairman of the relevant employing Authority if, in the light of the above criteria, he is in disagreement with the recommendations of the Committee. The same action would be apposite if the representative should be concerned about some irregularity of composition or procedure of the Appointments Committee.

4. If any of these difficulties arise, the College representative may be able to persuade the Appointments Committee to submit its recommendations to the employing Authority without informing the candidates. In any case, he should ask that his disagreement be minuted.

5. If action under 3 is to be undertaken, the College representative should tell the Appointments Committee what he proposes to do. (In Scotland, National Panel Members are asked to apply these guidelines and in cases of difficulty should inform the Chairman of the Scottish Division before writing to the Secretary of State.) He should then send a copy of the minority report, giving full reasons for his opinion, and any further relevant observations, to the President of the College as soon as possible. This information will be regarded as strictly confidential.

6. Because the role of an Appointments Committee is to recommend the candidate or candidates they consider suitable for the post, it is not appropriate for them to recommend a candidate who is not yet suitably qualified but who would become so after undertaking further training. They may, however, advise that a particular candidate who is at present qualified for the post would nonetheless benefit from particular further training before taking up his duties.

7. The application of these guidelines is intended to raise standards of psychiatric practice and will allow some flexibility of interpretation for excellent candidates.

8. College representatives are invited to keep the Registrar informed of any difficulty in interpreting these Notes.

College representatives are occasionally involved in committees where questions of racial discrimination or health may arise. College policy in such circumstances has not yet been formulated, but the following suggestions may be of assistance:

(i) As service on Advisory Appointments Committees could possibly result in members having to appear before a Tribunal in a race or sex discrimination case it would be prudent for members to make and keep in their own possession notes about the candidates or the proceedings of the committee where such an appeal seems at all likely. At the first indication of involvement in a tribunal a member is advised to notify his medical defence society.

(ii) It is not the task of the Appointments Committee to make a judgement on the physical or mental health of a candidate. If, however, serious doubt regarding health does arise during the course of an interview, the College Assessor should apply the usual criteria of suitability and may wish to make a recommendation for appointment subject to satisfactory medical examination.

\section{APPENDIX 1}

\section{Criteria for Consultant Posts in Psychiatry}

1. Before appointment to a Consultant post, whether in general psychiatry or one of the other psychiatric specialties, a candidate should normally have undertaken a basic training in psychiatry and hold the MRCPsych or equivalent qualification. If there is an outstanding candidate, or circumstances are highly exceptional, other relevant qualifications and experience may constitute an acceptable alternative.

2. The successful candidate should normally have reached the age of 32. but there is no bar to the appointment of younger applicants. 
3. Due weight should be attached to breadth of experience, participation in organized rotation schemes, periods spent abroad in relevant posts, and work in medical fields allied to psychiatry.

The view of the College is that the responsibilities of all Consultant posts include the function of training those in medical and related disciplines, so that some teaching experience and supervision of trainees is desirable in candidates for appointment as Consultant. Experience in research, especially if this has proved worthy of publication, will enhance a candidate's application. But even the most outstanding experience of this kind should not be allowed to over-ride the essential requirements laid down in (1) above.

4. The Joint Committee on Higher Psychiatric Training (JCHPT) has decided not to institute an accreditation procedure at this stage. Senior Registrar or equivalent posts have, however, been inspected and approved and the JCHPT urges College Assessors to ensure that candidates have been trained in such posts and that they are not normally appointed to the consultant grade before completing at least three years of higher training. For further details regarding the Joint Committee's requirements for specialist training, please see JCHPT Handbook, August 1983.

5. Specific requirements for various types of Consultant posts are as follows:

\section{(a) General Psychiatry}

Normally three years of recognized general professional training in psychiatry followed normally by at least three years of higher training in an approved training post. Exceptions may occasionally be made for outstanding candidates with other relevant experience (e.g. research or service overseas), but a minimum of five years training in psychiatry, including clinical research, is still required. Although part of the period of higher training can be spent working in other specialized fields, at least two years full-time (or part-time equivalent) must have been spent in a general adult psychiatry post educationally approved by the JCHPT specifically for the purpose of training in preparation for a consultant post in general adult psychiatry.

\section{(b) Child and Adolescent Psychiatry}

Basic training in psychiatry, which may also include time in a registrar post in child psychiatry, should have been followed by experience in all aspects of the specialty in a Senior Registrar training post, normally for a period of three years.

(c) Mental Handicap Psychiatry

Specialist training in mental handicap should be obtained at Senior Registrar level in a training scheme which can offer further experience in those aspects of mental handicap necessary to consultant psychiatric practice in this field. A candidate for a full-time specialist post in mental handicap should have held a Senior Registrar or equivalent academic post in a training scheme normally for a period of three years.

(d) Forensic Psychiatry

A candidate for a full-time specialist post in forensic psychiatry should have held a Senior Registrar or equivalent academic post in a training scheme normally for a period of three years. Evidence should be sought that a candidate has had adequate training in general psychiatry and in rehabilitation psychiatry. Experience in related fields should be given due weight.

(e) Psychotherapy

A candidate for a full-time psychotherapy specialist post should have held a Senior Registrar post in a training scheme for a minimum period of three years.

\section{(f) Psychiatry of Old Age}

Candidates should have held a Senior Registrar post in general psychiatry normally for three years, including a period of at least one year, but usually eighteen months full-time experience in psychiatry of old age. (g) Consultants in General Psychiatry with a Special Interest in a Named Specialty

Posts are often advertised for consultants to work in general psychiatry with a 'special interest' in one of the following subjectsalcoholism and/or drug addiction; rehabilitation; the psychiatry of old age; liaison psychiatry; behavioural treatments; mental handicap; forensic psychiatry; psychotherapy; and adolescent psychiatry. (Child and adolescent psychiatry cannot, however, be a special interest subject for a general psychiatrist.) Candidates for such posts need to have had substantial experience both in general psychiatry and in the special interest subject.

Candidates for 'special responsibility' posts should have undertaken two years' higher training in general psychiatry and not less than one year or its part-time equivalent in the area of special interest.

Candidates for joint posts should have undertaken not less than eighteen months in each of the disciplines.

(h) Special Hospitals

While most consultants in Special Hospitals will be forensic psychiatrists trained in approved posts, those trained in general psychiatry or in mental handicap with a special interest in forensic psychiatry could well contribute to the work of a Special Hospital. The consultant with a special interest in forensic psychiatry should have held an approved post for at least one year. With both, the forensic psychiatry and special interest posts training experience in a related field should be given due weight. It is important that the specialty and the special interest contribution are clearly identified beforehand and that these are reflected in the job description.

\section{APPENDIX II}

Advice to College Assessors serving on Advisory Appointments Committees concerning completion of higher training

There has been a view in both the College and in the JCHPT that the introduction of personal accredtation for trainees who have completed psychiatric training would lead to undue rigidity in training schemes and reduce our ability to respond to changing circumstances. By comparison with developments in medicine, where there are now over twenty recognized specialties each with an approved programme of training, our policy for psychiatric training has been a wise one.

The disadvantage of not adopting personal accreditation is that it is more difficult to identify candidates for consultant posts who have completed relevant and approved training. Furthermore, this peocedure is one of the tasks of Advisory Appointments Committees, where a great responsibility falls on College assessors. The difficulty in this arrangement is that approval of training and recognition of completion of training is divided between two bodies, which are linked rather loosely through the College. The satisfactory working of the present system of higher training in psychiatry depends on satisfactory liaison between the JCHPT and the College.

The key point in the procedure is the assessment of training made by the College assessor at Advisory Appointments Committees. For this to be satisfactorily carried out the College assessor needs to be familiar with JCHPT and College policies on training both at basic and higher levels, to have satisfactory information on the candidates who present themselves, and to be able to apply the appropriate criteria in the setting of the Advisory Appointments Committee.

The JCHPT criteria for completion of higher training in psychiatry, leading to eligibility for appointment to consultant posts are broadly as follows:

1. Posts which are full-time in General Psychiatry, Child and Adolescent Psychiatry, Mental Handicap, Forensic Psychiatry or Psychotherapy require the completion of three years of a training programme approved by the JCHPT for that purpose. 
2. For appointment to special interest posts with responsibility for the organization of services, there is a requirement of at least one year of training in the subject of special interest approved by the relevant specialist advisory committee of the JCHPT; and two years approved training in the core discipline which is normally General Psychiatry.

3. For appointment to posts with work divided equally between two disciplines (usually General Psychiatry and Mental Handicap Psychiatry) there should be at least 18 months' experience in each area, both of which schemes must be approved by higher training by the relevant SACs.

4. Training must be in substantive posts, although three months' experience as a locum Senior Registrar in a post approved for training may be included in the total requirement of three years; and three months' experience as a locum consultant during secondment from an approved scheme may also be accepted as a part of higher training.

5. Experience in full-time research may be recognized for periods up to two years, provided that there are four sessions per week of clinical work of whatever nature. Research experience for longer peiods may be recognized for higher training in certain specified posts.

6. Experience as Lecturers with Honorary Senior Registrar status is fully recognized for higher training.

7. Training undertaken on a part-time basis must be for five sessions or more per week, have a similar composition to full-time training and extend over a proportionally longer period.

\section{Distinction Awards in Psychiatry (England and Wales)}

As a member of the Central Committee on Distinction Awards for the past few years, it has occurred to me that we might improve our position in the stakes by endeavouring to co-ordinate the advice rendered.

I believe that local support is of pre-eminent importance, especially at the ' $C$ ' level, and even for Higher Awards. This support comes via local 'C' Awards Committees and Regional Higher Awards Committees on which the College is not represented as an Institution.

The College has an Awards Adviser (a separate appointment from the College Regional Adviser) in each NHS Region in England and Wales, who meets the Chairman of the Central Committee on his rounds. They also participate in the deliberations of the College Distinction Awards Committee, which includes representatives of College Divisions, Sections and Groups. Although there is clearly some overlap, there are also substantial differences between the lists of names put forward through College channels from those emerging out of the local Committees. There may be good reasons for this disparity, and one would not wish to see a monolithic and exclusive selection process developing.

When Professor Linford Rees was President, he wrote a 'Note' for the Bulletin on Distinction Awards (March 1978, page 39). He outlined very clearly the various sources of information and advice which were used by the NHS Advisory Committee on Distinction and Meritorious Service Awards in its deliberations.

At the same time I believe that steps could be taken by College Awards Advisers to hold discussions each year with the corresponding Chairmen of the College Divisions, and with the psychiatrist members on local ' $C$ ' Awards and Higher Awards Committees. In this fashion a smaller number of names will come to the NHS Central Committee from a larger number of sources, with, hopefully, a facilitating effect on surmounting the threshold for an Award.

K. RAWNSLEY

\section{Central Committee on Distinction Awards}

College nominated advisers on Awards in the Regions

Northern: Dr K. Davison; Yorkshire: Dr J. M. Roberts; Trent: Professor F. A. Jenner; East Anglia: Professor Sir Martin Roth; North West Thames: Dr K. GranvilleGrossman; North East Thames: Dr S. Crown; South East Thames: Dr P. H. Connell; South West Thames: Professor A. Crisp; Wessex: Professor J. L. Gibbons: Oxford: Professor M. Gelder; South Western: Dr J. B. Gordon-Russell; West Midlands: Dr J. Harrington; Mersey: Dr M. D. Enoch; North Western: Dr J. Johnson; Wales: Dr D. M. Shaw.

\section{Regional 'Higher' Awards Committees, 1985 Psychiatrist members}

Northern: Dr K. Davison; Yorkshire: Dr J. M. Roberts, Dr N. E. Crumpton; Trent: Professors F. A. Jenner and S. Brandon; East Anglia: nil; North West Thames: Dr P. J. Dally, Dr I. C. Lodge Patch; North East Thames: Dr S. Crown, Dr A. Bentovim; South East Thames: Professor R. H. Cawley; South West Thames: Professor A. H. Crisp; Wessex: Professor J. L. Gibbons; Oxford: Professor M. Gelder, Dr D. C. Watt; South Western: Dr J. B. Gordon-Russell; West Midlands: Dr J. A. Harrington; Mersey: Professor J. Copeland, Dr M. D. Enoch; North Western: Professor W. I. N. Kessel, Dr J. Johnson; Wales: Professor K. Rawnsley, Dr J. M. Hughes.

\section{Regional 'C' Awards Committees, 1985}

Psychiatrist members

Northern: Dr I. C. A. Martin, Professor D. Eccleston; Yorkshire: Dr M. Segal, Dr P. J. Beynon, Dr J. M. Roberts; Trent: Dr D. A. Toms, Dr H. M. Park; East Anglia: Dr R. Devine; North West Thames: Dr J. Steinert, Dr C. M. Tonks; North East Thames: Dr J. D. Hailstone, Dr J. L. Swift; South East Thames: Dr P. K. Bridges; South West Thames: Dr P. B. Storey; Oxford: Dr J. Aitken, Professor M. Gelder; Wessex: Dr J. S. Grimshaw, Dr D. H. Dick; South Western: Dr H. G. Morgan; West Midlands: Dr G. Milner; Mersey: Dr B. K. Brooker; North Western: Dr J. T. Eliot, Professor W. I. N. Kessel; Wales: Dr T. G. Davies. 